\title{
A Virtual Environment for Problem-Based Learning in Software Engineering Education
}

\author{
Bruno Bessa \\ Centro de Informática \\ Federal University of Pernambuco \\ Recife, Brazil \\ brb@cin.ufpe.br
}

\author{
Simone C. dos Santos \\ Centro de Informática \\ Federal University of Pernambuco \\ Recife, Brazil \\ scs@cin.ufpe.br
}

\begin{abstract}
PBL (Problem-Based Learning) is a constructivist teaching method that uses real-life problems to develop skills and attitudes in students to solve them. This involves the inclusion of essential practices that are based on collaborative work and task management. As PBL is process-oriented, it is necessary to guide students in the definition of the solving process, ensure that students follow this process and monitor all the work, realizing improvements when necessary. In view of this, Virtual Learning Environments (VLE) can be very useful to support PBL processes in blended learning, providing a technological environment where the learning process can be managed. However, the literature shows that technological tools to support a PBL approach have only been explored to a limited extent and not effective. In this context, this paper proposes the "PBLCoach", a VLE composed of a set of structured and measurable activities to support PBL in the Software Engineering Education. A case study was carried out with the aim of assessing the utility and usability of PBL-Coach in blended learning context, and the results showed a good acceptance level of its use.
\end{abstract}

PBL; Learning Environment; Software Engineering Education

\section{INTRODUCTION}

New methods of teaching and learning have been adopted as a means of supporting the changes in the teaching and learning procedures that are aligned with the new requirements of the job market and a redefinition of the roles of those involved in education. For example, Problem-Based Learning (PBL), which can be defined as a method of teaching that is centered on the student, draws on real-life problems to trigger and encourage the learning of concepts by improving the skills and attitudes necessary to attempt to solve them. When contextualized in a realistic setting, the problems drive the students to seek ways of solving problems and acquire the necessary skills and attitudes to do this and thus be valued in their professional lives [1]. In this area, the recognized curricula in the area of Computing, such as the ACM/IEEE Computer Science Curricula, are being redefined in accordance with the inherent features of PBL, such as group learning, collaboration, problem-solving abilities, interpersonal communication and management skills.

In [2], the authors present a systematic mapping of the use of PBL in teaching Computing, describing the main features for an effective approach to PBL, together with its potential benefits and likely challenges. They stated that the benefits of PBL are closely linked to the methods and instruments of management, which allow the planning, execution, monitoring and continuous improvement of the solving-process conducted by students.

With regard to teaching Engineering Software in particular, the adoption of Information Communications Technology (ICT), such as Learning Management Systems (LMS) and Virtual Learning Environments (VLE), has not allowed teaching and learning to reach its full potential with regard to planning, monitoring and assessment [3]. In fact, many cases have a shortage of computer instruments and are restricted to limited ways of assisting the teaching and learning process, focused on collaborative work, but not include the definition of educational objectives, the linking between tasks and objectives, process to assess this work and its results. In [4], the authors make a comparison between a key list of VLE that are adopted in education. Among these, they underline the importance of the Open Simulator, Second Life, Active Worlds, Project Wonderland and Open Cobalt systems. On the basis of this analysis, it can be concluded that most of the systems are able to support online education, whether in terms of content or centered on the teacher, but there are only a few data that effectively show the support of PBL.

In [5], the author stresses that a VLE that is suited to PBL must be geared towards teamwork and be focused on a discourse that is concerned with the collaborative construction of knowledge. The author defines a particular term for this environment, "CMCPBL" (Computer-Mediated Collaboration for PBL). This refers to three significant features of this discourse and uses the work of [6] as a benchmark: (1) A focus on the background of the problems and an in-depth understanding of this problem; (2) Construction of open and collaborative knowledge; (3) Inclusion of all the participants in the learning process. In the light of these specific features, this work examines a set of activities based on the principles and features that arise from learning theories about PBL. These activities will be supported by a virtual learning environment with interactive technological resources, called PBL-Coach. The purpose of PBL-Coach is to support the implementation of the PBL method and ensure that it is adopted in compliance with its principles. 
The proposed environment was validated by conducting a case study in the open education, which involved sixteen students and three teachers in a course on Agile Project Management on the period March-June, 2016. This study sought to answer two questions: "Q1) What is the degree of usefulness of PBL-Coach in carrying out environmental activities based on the principles and main features of PBL?"; "Q2) What is the degree of usability of the PBL-Coach from the standpoint of the teachers and students?". The Technology Acceptance Model (TAM) was used as an assessment tool.

\section{MAIN THEORETICAL REFERENCES}

\section{A. PBL Principles}

In [7], Savery \& Duffy set out a set of eight instructional principles for PBL, namely: (i) Anchor all learning on activities to a larger task or problem; (ii) Provide support for engaging the student on the task or problem; (iii) Design an authentic task; (iv) Design the task and the learning environment to reflect the complexity of the environment for which the students should have the skills to interact in, at the end of the learning; (v) Give the student ownership of the process used to work out the solution; (vi) Design the learning environment to support students' thinking while challenging them; (vii) Encourage the testing of ideas against alternative views and contexts; (viii) Give opportunity for reflecting on learning and what has been learned. In addition, the authors in [ref] include more two PBL principles, completing a list of "10 PBL principles": (ix) PBL lays down a process of multi-directional teaching and learning; (x) PBL is supported by planning processes and continuous monitoring. Regarding the CMCPBL features commented in Section 1, the principles (i), (ii), (iii), (iv) and (vi) are related to feature (1), that emphasize the importance of students deal with a real and relevant problems into an authentic learning environment; while the principles (v), (vii) and (viii) are related to feature (2), with focus on collaborative knowledge; and (ix) and (x) related to feature (3), that reinforce the interactions among all participants of the learning environment.

\section{B. $x P B L$}

Although PBL is based on principles, it does not define a single methodology for their application within an educational setting. In [3], the authors put forward a methodology called $x P B L$, with the aim of ensuring that when PBL is employed for the teaching of Computer Studies, it is implemented in an effective, authentic and rigorous manner. According to the authors, the authenticity of the learning environment for PBL can be preserved if the following factors are taken into account: 1) the adoption and practice of real problems; 2) the definition of the human resources involved, together with their clearly defined functions and responsibilities; 3) theoretical content aligned with problem- solving; and 4) the adoption of the kind of development processes and assessment procedures employed by the market; 5) those involved are within an environment that reflects the reality of the job market. By preserving the learning environment and faithfully adhering to the guidelines of the PBL methodology, what is taught to the students can be rendered much more effective as a means of preparing them for their professional lives.

In [1] and [8], the authors show that it is possible to ensure that PBL is adopted in an effective way when it follows the stages of a well-defined process that encompasses planning, execution, monitoring and assessment and is geared towards making continuous improvements. These stages rely on the PDCA cycle (Plan, Do, Check and Act), which is a methodology that is basically designed to assist in the diagnosis, analysis and prognosis of organizational problems, and is ideally suited to the management of the teaching/learning process in PBL.

\section{Delisle solving-process}

In order to help students to better understand the problem chosen and propose a more adequate solution to it, was developed a dynamic that made use of Delisle problem-solving model [9]. The model is composed of four aspects that must be observed: 1) Ideas: possible solutions to the problem; 2) Facts: information about the problem; 3) Hypotheses, identification of learning problems to solve the problem and; 4) Plan of Action: strategies, information resources and other information that lead to the resolution of the problem. Figure 1 illustrates the solving-process defined by Delisle.

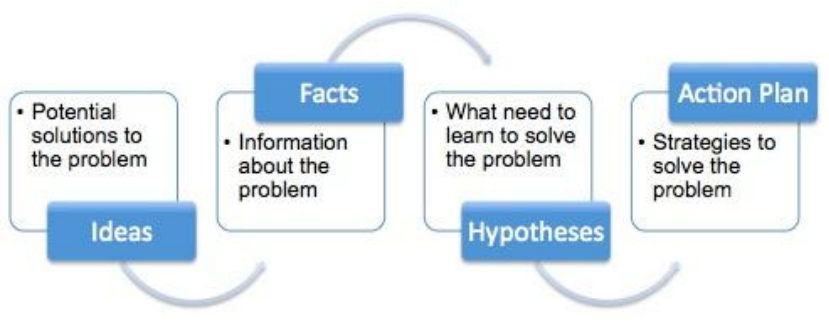

Figure 1. Solving-process by Delisle.

\section{METHOD: DESIGN SCIENCE RESEARCH}

The guidelines for the scientific method which shapes the different stages of this research study, can be found in Design Science Research (DSR), a research method which involves analyzing the use and performance of artifacts that are designed to understand, explain and improve the behavior of specific factors in the domain of Information Systems [10]. The basic principle of Design Research is that the knowledge, understanding and solving of a problem are acquired in the construction and application of an artifact within the context of a particular problem. Therefore, the DSR method was adopted in five steps:

1) Understanding the Problem: to obtain a clearer understanding of the teaching method. The aim of this activity was to find out about the principles and factors that, in the view of several authors, govern the PBL method. The second activity was to highlight the challenges and any particular obstacles that might face the PBL method. As a result, it was possible to draw up a list of problems regarding the management of PBL, such as the following: the difficulty of setting out a procedure to assist the students with problem-solving, the complexity of assessment, and how to teach managerial skills to students with a technical background, among other factors. 
2) Suggestions step was to make conjectures about how technology can be used to facilitate learning in the PBL approach. The second activity was to design a model for problem-solving; this had in mind the xPBL methodology commented in Section II.B, which establishes specific means of panning and implementing PBL in the teaching of Computer Studies. As a result, a conceptual model of the learning environment was originated, as shown in Section IV.

3) Development step was to define the architecture, tools and development processes. This led to the design of the software artifacts of the PBL-Coach assessed by real users, as described in Section V.

4) Assessment step was to understand the preparation, application and analysis of the artifacts, together with the end users, with the aim of determining, in the first moment, the usability and utility of the PBL-Coach. This resulted in the setting out of performance measurement standards.

5) Conclusion stage was to understand what we learn. It should be mentioned that the assessment procedure foresees future iterations.

\section{PBL-COACH IN PDCA CYCLE}

The conception of PBL-Coach was based on the main references commented in Section II: the ten PBL principles; the xPBL methodology; and the Delisle solving-process. As in PBL, the use of PBL-Coach follows a process composed of prescriptive activities. These activities allow the management of the teaching and learning process, since they rely on the PDCA cycle as foundation. Moreover, there is a relation between these activities and the PBL principles, explicitly pointed out in next sections. Figure 2 illustrates the process of using PBL-Coach within the planning, execution monitoring and improvements steps, highlighting the activities of each one.

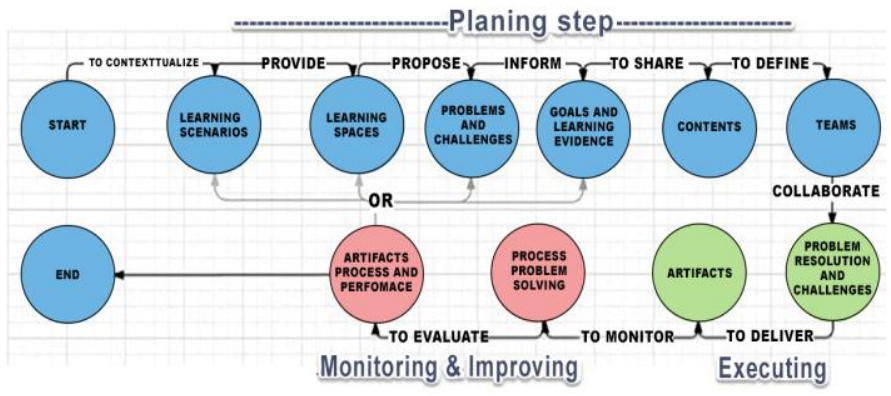

Figure 2. Interface to manage problem and challenges by teachers.

In the Planning step, six activities stand out: "learning scenarios", in which the teacher/tutors defines a learning scenario that correspond to real circumstances and to allow that students can reflecting on a situation where they should be enabled to assimilate interests of their learning; "learning space", where the teacher/tutors should make a place available for the students where they can do research and share technology, especially designed to encourage the collaboration among them (3D interface, as shown in Figure 4); "problems \& challenges", when the teacher set real problems that challenge the students to seek to explore matters, and challenges that represent a partial goal in the solving-process controlled by schedules and deliverables; "goals and evidences of learning", when the teacher defines the learning objectives, describing observable knowledge and the skills required from the students; "content", related to sharing of text-based files, presentations, spreadsheets and so on; and "teams", when teacher/tutor form heterogeneous teams in which the different skills of each member can be complemented to achieve results.

Regarding Execution Step, two activities were defined: "solving of problem \& challenges", Where students discuss and debate their knowledge about potential solutions, extract facts about the problem, define hypotheses about the challenges (according to Delisle's problem solving process) and also define the tasks that are required to solve the problem (action plan), dealing with the different phases of the workflow; and "artifacts", that consist in creation of web-based documents, such as spreadsheets and presentations, among other kinds of collaborative work.

Finally, the Monitoring and Improving steps define two activities: "monitoring resolutions", when the teacher/tutors assess artifacts, procedures and performance produced by students; and "continuous improvements", when the teacher should find out what difficulties students have, deal with any queries, provide feedbacks and check the deliverables of the teams.

\section{USING PBL-COACH IN SOFTWARE ENGINEERING EDUCATION}

This section describes the use of the PBL-Coach in the Agile Project Management module of an undergraduate course in Software Engineering. There is a total of 60 contact hours over 4 months (March-June 2016), the educational goal being to train 16 students (organized in four teams) in good practices in Agile Project Management.

To conduct the course, planning was carried out by the pedagogical team comprising three teachers with project management and PBL experience. This plan followed the guideline proposed by xPBL (mentioned in Section II).

\section{A. Planning}

In the Planning step, the teachers had access to a specific URL of PBL-Coach. The real life client (the owner of the problem) can "submit problems" by giving the name and email address and by publishing a video or file in a PDF format, so that it is contextualized. In this case, each team was supported by one real client, who presented a list of problems related to software solutions. The teachers created learning scenarios and "chose the most effective problems". After this initial selection, the teachers were able to bring together their educational objectives by giving guidance to the students with regard to their learning goals and their choice of strategies to achieve them, as well as the information that would provide support for their chosen problem-solving.

Figure 3 shows the interface for the management of problems and challenges. This resource makes it possible to store problems in a shared repository and carry out searches that cover a wide range of information of interest. It will also make it possible to visualize the problems through specific information (presentations and video provided by real clients, for example), as well as to plan challenges to solve problems 
(into a specific period) or choose new problems on the basis of pre-existing problems.

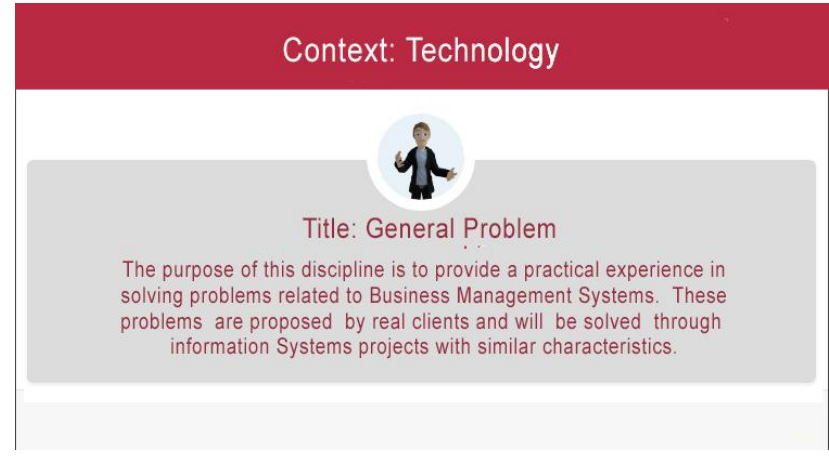

Figure 3. Interface to manage problem and challenges by teachers.

Following this, the teachers created immersive learning environments (learning spaces) and invited people or "human capital" (students, teachers and clients - depending on the role they played) to form learning groups. This resource is based on the model for learning environments of Google Learning Space (Figure 4), promoting meeting and sharing of technological resources of the PBL-Coach.

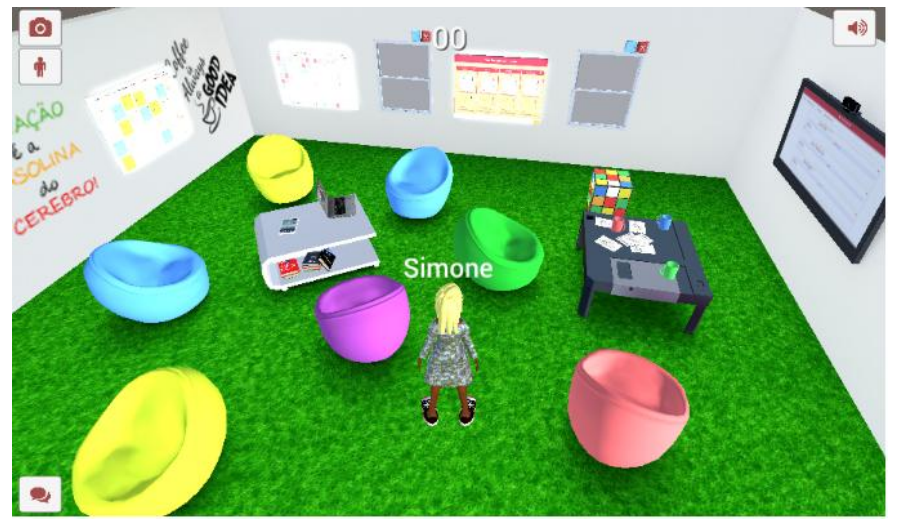

Figure 4. Interface to manage problem and challenges by teachers.

All this "human capital" that had been invited, was notified by e-mail and supplied with information about access to the

virtual learning scenario in PBL-Coach.

\section{B. Execution}

In the execution step (Do), the students had access to PBLCoach and began to see the problems that had been set. Moreover, they were able to clear up any uncertainties about the terms, situations, words or expressions they were unable to understand. They also visualized and coped with the challenges and learnt to understand what subjects or issues needed to be studied to overcome them. This understanding entailed identifying learning objectives/issues. Following this, the students revealed their knowledge and investigated facts, hypotheses and ideas with regard to the challenge-problem, through an interface called "analysis of solutions" based on Delisle process described in Section II.C. Figure 4 shows the interface for the analysis of solutions for problems-challenges. This resource provides a board, which establishes the analytical procedure for monitoring how students find solutions to problems. It also offers the students a means of thinking about a problem in depth and reaching a conclusion by means of the following sequence of solving-process proposed by Delisle.

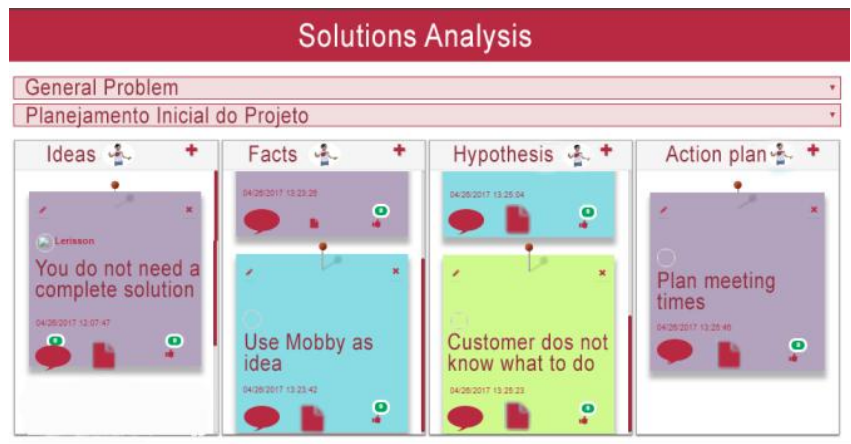

Figure 5. Analysis of solutions board.

Each member of the group could remember different things and this turned the discussion into an opportunity to learn, posting opinions directly in the analysis solutions board. It was important to show respect for the opinions of other people. The next step was to define the tasks, which could meet the expectations of the team, elaborating an action plan in a task management board. Figure 6 shows the interface for task management. This resource adopts the agile Kanban approach, which shows the workflow stages with the activity attributes of members of the team. In PBL-Coach, the Kanban board is organized in columns for the following stages: "to do", "doing", "done", "checked" and "obstacles". In this way, the boards are divided into columns, which represent the current state of each task. Each team must to manage its board, defining tasks and executors for them. Its value is that it can still operate as a management approach for agile practices and promoting selfmanagement skills.

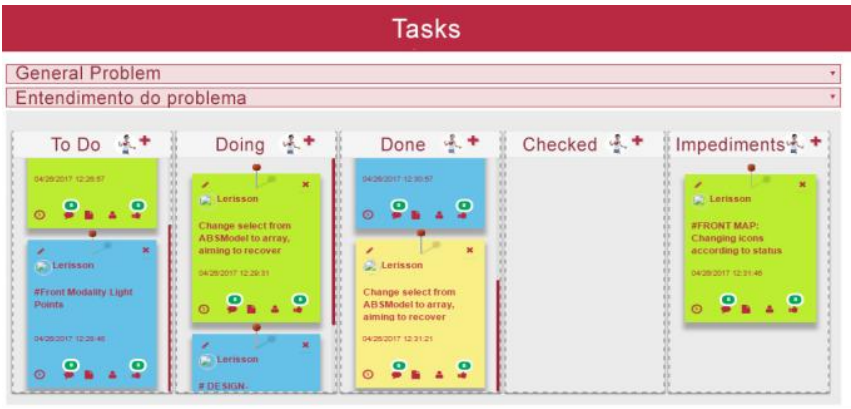

Figure 6. Interface to manage problem and challenges by teachers.

These tasks were transparent in so far as all the necessary information was disclosed to all human capital involved in teaching and learning process (students, teachers, clients), improving the communication and integration among them. The students also create documents, spreadsheets and presentations in a collaborative way, as well as holding remote meetings with the members of their teams, teachers and clients. About meetings, the students can also access an immersive learning environment (learning space), as shown in Figure 4. 


\section{Monitoring and Improving}

In the monitoring and improvement stages (Check and Act), the teachers identified any difficulties the students might have in solving the challenge-problems, analyzing results or carrying out tasks. With the teachers constant support and supervision, along with the "like" button and comment sections in the cards at PBL-Coach, the ideas that the students posted in "Analysis of solution board" there could be continuously validated. This way, we were able to give positive feedback, guiding the students towards the right path, from the moment they found their first ideas to the moment they actually finished their projects.

They could also assess the degree of involvement of each group or each student with regard to the activities and conduct a 360 degree evaluation. A 360 degree evaluation took place between all students. This kind of evaluation was chosen because it provides a self-evaluation, plus a pairs and teachers evaluation. We also opened up for verbal feedback and suggestions from the students on the project as a whole. PBLCoach also automatically generates a graph that quantifies how much the students actually entered data, commented and got positive feedback in the software. This production of visual graphs is actually one of the outputs for the process element guidelines proposed in [11].

\section{ANALYZING UTILITY AND USABILITY OF PBL-COACH}

The assessment stage of the research was characterized as descriptive. It involved data collection, which was carried out by means of a questionnaire based on TAM (Technology Acceptance Model) that was answered by sixteen students and three teachers who made use of the PBL-Coach, described in Section V. The questionnaire with 8 questions was available by Google Forms.

\section{A. Utility}

The purpose of utility evaluation is to assess the compliance of PBL-Coach with the PBL approach, regarding its principles. Figure 7 brings together all the results obtained in the questionnaire with regard to the utility dimensions. A multichoice system was adopted where the questions are set out as alternatives variables and the respondents must choose one of them. This was based on the Likert Scale, which has a format that distinguishes between the following categories: 1) I Strongly Agree, 2) I Agree, 3) I Don't Know, 4) I Disagree and 5) I Strongly Disagree.

The first and second question asked the interviewees about: Q1) if PBL-Coach provides support for the research question, analysis and problem-solving, and addresses the challenges; and Q2) if it makes immersive learning spaces available for the students so that they can be involved in learning practice, as well as activities where they are given feedback by their peers and teachers. It can be observed that for Q1 $66.67 \%$ of the answers were obtained the "I strongly agree" category, and $33.33 \%$ in "I agree", whereas on the case of Q2, 50.00\% were obtained within the "I strongly agree" category and $50.00 \%$ within "I agree". This level of agreement was maintained in both variables, which means that PBL-Coach helped to extend knowledge by giving support to problem-solving. The system also provides a virtual learning environment which allowed the students to work closely together; this because this learning strategy keeps them in contact with their peers when addressing differences of opinion arising from the answers of the interviewees.

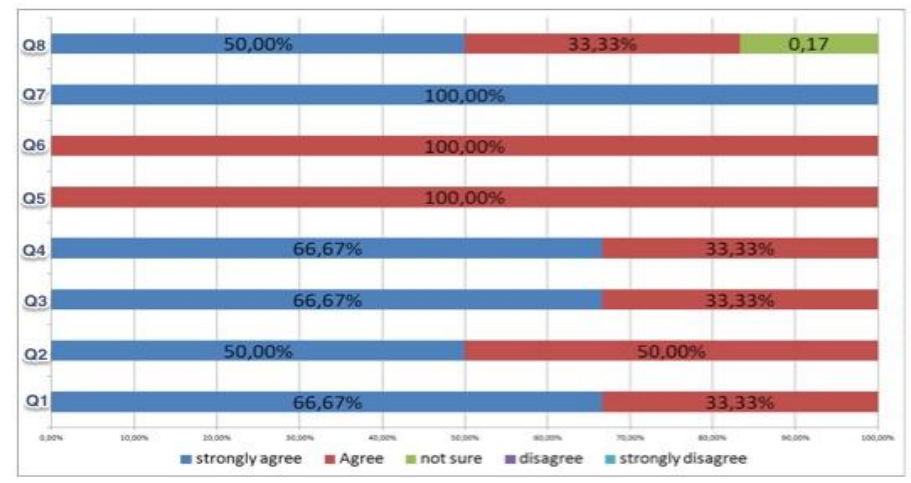

Figure 7. Utility evaluations of PBL-Coach.

The third and fourth variables asked the participants: Q3) if the PBL-Coach allows to include (and have access to) information; and Q4) if it allowed an exchange of information among all involved in teaching and learning process, so that they could help each other in a way that fostered a multidirectional approach to teaching. It is worth noting that in both Q3 and Q4, the answers obtained related to the "I strongly agree" (66.67\%) and "I agree" (33.3\%) categories. This level of agreement was maintained in both the affirmations, which means that PBL-Coach can assist in ensuring collaboration and the sharing of information.

The fifth, sixth and seventh questions asked the interviewees respectively: Q5) if PBL-Coach enables the students and teachers to communicate with each other; Q6) if it assisted the students and teachers in planning their activities; and Q7) if it gave the students the freedom to make decisions about the problem that was set and how to reach a solution. It should be noted that in Q5 and Q6, the answers obtained were related to the "I Agree" category (100\%), and "I strongly agree" (100\%) for the question Q7. The level of agreement was maintained in all the variables, which means that PBL-Coach can lead to greater interaction between the teacher and student in different situations that occur both inside and outside of the classroom, using the PBL-Coach. This can encourage students to adopt a critical spirit of inquiry and stimulate active learning.

Finally, the eighth question asked the participants if the PBL-Coach benefits the monitoring and improvement of the way learning is constructed. It can be seen that, most of the answers obtained, related to "I Strongly Agree" (50.0\%) category, "I Agree" (33.3\%) and "I Don't know" $(16.67 \%)$. The level of agreement was maintained in both affirmations, which means that PBL-Coach benefits the monitoring of the way students undertake their learning. The reason for this is that, the PBL-Coach follows a series of steps proposed by xPBL methodology that must be undertaken, or in other words, it involves procedures and graphical resources, that makes it easier to assess the performance of the students.

\section{B. Usability}

The usability evaluation concerns to assess the degree to which the users believed that the PBL-Coach is "usable" during 
the APM course. This evaluation was carried out in three cycles, with clear evolutions in each one. Many aspects were considered in this point, such as the perception of use, interface use, standardize of terms, system performance, ease of use, and so on. Here, only general perceptions are showed, due space limitations. Improvements were implemented in the system at the end of each cycle, based on these assessments. Figure 8 shows the evaluation related to general reactions to the PBLCoach. As is shown, the average growth related to general reactions was 2.7 in the first cycle, growing to 3.8 in the second cycle and 3.9 in the third cycle, considering the scale shown in the graphic of Figure 8 (terrible - excellent; frustratingsatisfactory; tedious-stimulant, and so on). This result showed a positive perception of participants from the APM course, commented in Section V.

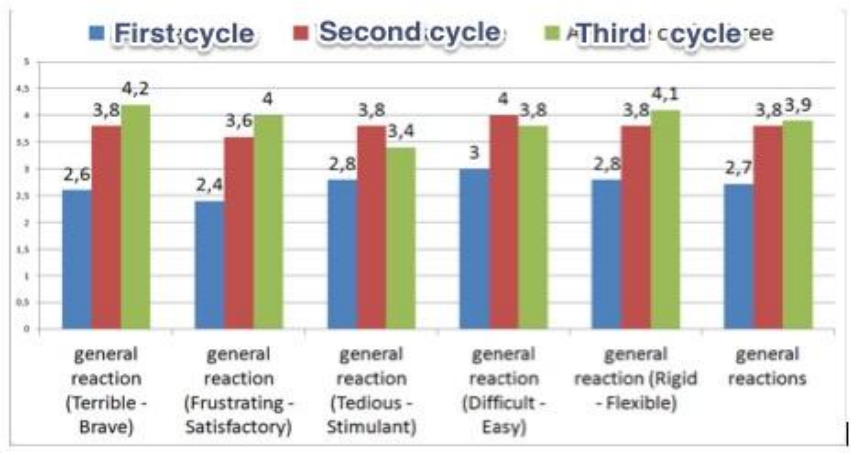

Figure 8. General reaction about usability.

Figure 9 shows the evaluations related to use of PBLCoach: "start to use", "learning curve to use" and "general perception of use". The graph of Figure 9 indicates relevant evolutions in each of these dimensions, very close to the positive extreme of the scale (for example, difficult-easy).This result indicated a good level of acceptance and indicates the easily to learn to use the PBL-Coach.

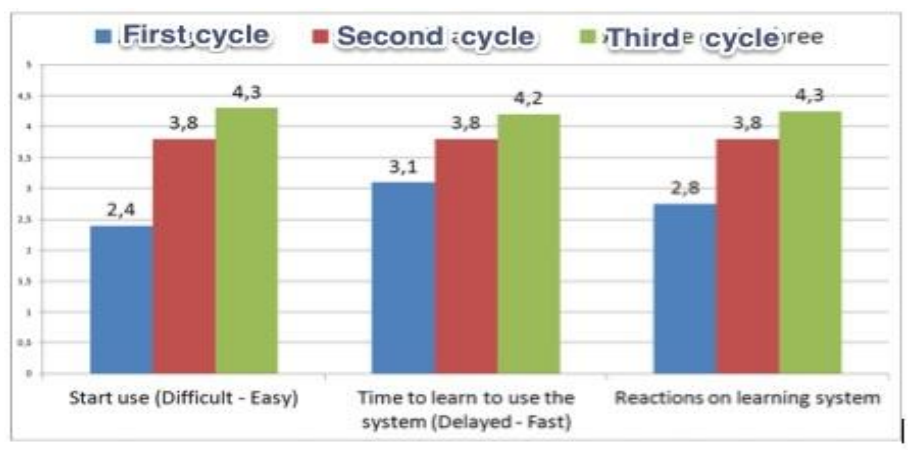

Figure 9. Interface to manage problem and challenges by teachers.

\section{CONCLUSIONS}

Considering the effectiveness of the PBL method, this paper presented a virtual learning environment with interactive, technological resources, called PBL-Coach, the aim of which is to oversee the implementation of the PBL method and ensure that it adheres to its principles. A case study yielded results that were favorable to the PBL-Coach, which it validated together with a group of users. In general terms, it was clear that PBLCoach proved to be suitable for attaining its objectives. On the basis of the results obtained from perceived utility, it can be concluded that the use of PBL-Coach makes it possible to oversee the implementation of the PBL approach. This approach is also able to cater for the needs of a learning environment that is centered on the students and aligned with a learning methodology, management processes and collaborative tools. It should also be underlined that PBLCoach does not only give support to the planning, execution and monitoring of learning but also foster solutions analysis and task management skills.

Finally, in spite of the positive results for the initial assessment of usability and utility, it should be stressed that, although the environment is a necessary and powerful condition, it is not the only feature required for an effective learning process. It is the activities carried out by students during the teaching/learning process that determine to what extent learning has taken place and the involvement of the teacher in the environment also helps to foster this learning. In view of this, there are new kinds of ongoing validation that are being undertaken from the perspective of the utility and usability of this environment in real-life cases.

PBL-Coach is currently being used in three educational programs at a professional and academic level, and this confirms its importance since it has created situations of interest for teachers who have decided to use this environment in the schools and universities where they teach.

\section{REFERENCES}

[1] Figuêredo C.O., Santos S.C.,Alexandre,G.H.S.andBorba P. H. M.(2011), "Using PBL to develop Software Test Engineering", CATE, Cambridge, UK.

[2] Oliveira, A. M.; Santos, S. C.; Garcia, V. C. . PBL in Teaching Computing: An overview of the Last 15 Years. FIE, Oklahoma, EUA., 2013.

[3] Santos S. C., Furtado F., Lins W. "xPBL: a Methodology for Managing PBL when Teaching Computing”, FIE, Madrid, Spain, 2014.

[4] Kahiigi, E.K., ekenberg, L., hansson, H., tusubira, F.F., danielson, M. 2008. Exploring the e-Learning State of Art. The Electronic Journal of eLearning $6.77-88$.

[5] Savin-baden, M. 2003. Facilitating Problem-Based Learning. McGrawHill Education (UK). 170 pages.

[6] Scardamalia, m.; Bereiter, c. Adaptation and understanding: A case for new cultures of schooling. International perspectives on the design of technology-supported learning environments, Mahwah, NJ: Erlbaum., p. $149-163,1996$

[7] Savery, J.R.; DUFFY, T. M. Problem Based Learning: An instructional model and its constructivist framework. Educational Technology, 1995, 35, p. 31-38.

[8] S. C. Santos and A. Pinto, "Assessing PBL with Software Factory and Agile Processes", CATE, Naples, Italy, 2012.

[9] Delisle, R (1997). How to use problem-based learning in the classroom. ASCD: Alexandria, Virginia, EUA.

[10] Vaishnavi, V.; kuechler, W. Design research in information systems. 2004.Britain, S. and Liber, O. 1999. A Framework for Pedagogical Evaluation of Virtual Learning Environments. Environments.

[11] S. C. dos Santos. "PBL-SEE: An Authentic Assessment Model for PBLBased Software Engineering Education". Transaction on Education. IEEE, 2016. 